\title{
EFFICACY OF ANTI-HYPERTENSIVE THERAPY IN HYPERTENSION PATIENTS ATTENDING IN TERTIARY CARE HOSPITAL.
}

\author{
Dr.Kamal Kumal, Dr, Suraya Bahadur Hamal, Dr. Manoj Koirala, Dr. Bishow Baral. Dr. Amrit K.C, Pokhara
}

Pokhara Academy of Health Sciences, Western Regional Hospital, Nepal

Academy of health Sciences, Kaski, Pokhara, Nepal

\begin{abstract}
Introduction:One of the most common causes for morbidity and mortality in the world is uncontrolled hypertension. Our study was conducted in Pokhara Academy of Health Sciences because of easy availability of adequate patient required for the data. The aim of the study is to follow up hypertensive patient and the control of their blood pressures after taking antihypertensive medications.Materials and Method:Antihypertensive medicine use, co morbidities and data regarding blood pressure was abstracted from medical records of 226 patients from medical out patient department of Pokhara Academy of health Sciences from April 2017 to August 2017. Controlled blood pressure is defined as systolic pressure $<140 \mathrm{mmHg}$ and diastolic pressure $<90 \mathrm{mmHg}$ that in diabetic patient SBP $<130$ $\mathrm{mmHg}$ and DBP $<80 \mathrm{mmHg}$. Data was analyzed and entered in SPSS version 20.Result: $46.9 \%$ patients had control blood pressure within normal range. Calcium channel blocker was theone which significantly controlled the blood pressure in our multivariate analysis (OR, $1.93 ; \mathrm{Cl}, 1.06,2.51$ ), likewise number of two or more prescribed antihypertensive drugs, diabetes, Age related; (OR, 1.88; Cl 1.08, 3.27; OR, 1.24, Cl, 0.73, 2.11; OR, 0.51, Cl, 0.29, 0.89) respectively.Conclusion In this study, poor blood pressure control is seen as an important public health concern. Diabetes and age related (above 60 years of age) had poor blood pressure control which posses higher risk and can lead to co- morbidities. Further studies are needed to assess current outcomes in other centers as well.
\end{abstract}

Key words: Hypertension, antihypertensive, cardiovascular, Pokhara Academy of Health Science 


\section{Introduction}

Hypertension is major public health challenge world wide [1]. In 1980 high blood pressure patients were 600 million and 1 billion in 2008[1] where Africa and other parts of the world was seen to have $40 \%$ prevalence [1]. Premature mortality in terms of lost life of CVD has globally increased from 23.3 million (1990) to 37 million (2010) in south East Asia. Prevalence of hypertension among the young adults aged 25 years was $40 \%$ in 2008 [2]. In health care system increased blood pressure is major problem and it is the risk factor for cardiovascular diseases, stroke as well as coronary heart disease [2]. Heart failure, renal failure, eye complications (like retinal hemorrhage) and peripheral vascular disease are the complications of the high blood pressure [3]. Hypertensive patients with controlled blood pressure are in less risk of cardiovascular disease $[4,5]$. To provide basic guide on controlled blood pressure to public health, surveillance to determine blood pressure and its control is important. However we don't have enough data on the level of control of blood pressure in patients of our region. Mathenge $W$ etal showed that $24 \%$ patients receiving antihypertensive medicine actually had blood pressure within normal level [6].

A study shows that primary open angle glaucoma was significantly associated with hypertension

and diabetes mellitus which were 2.05 times higher in Gurung ethnicity than others in Nepal and over all, hypertension patient have 2.72 times more risk of having primary open angle glaucoma [8].

\section{Material and methods}

This is the cross section observational study which included 226 hypertensive patients from Pokhara Academy of health sciences between April 2017 to August 2017. All the data were analyzed by using SPSS 20. According to guideline of seventh report of the Joint National Committee (JNC), Hypertension with diabetes mellitus, target blood pressure were defined as < 130/80 while in non diabetic patient target blood pressure was defined as $<140 / 90 \mathrm{mmHg}$. Patient who had $\geq 140 / 90 \mathrm{mmHg}$ were taken in our study and further categorized in the following stages. Stage I (SBP 140-159 $\mathrm{mmHg}$ or DBP $90-99 \mathrm{mmHg}$ ) stage II (SBP $\geq$ $160-179 \mathrm{mmHg}$ or DBP $\geq 100-109 \mathrm{mmHg}$ ) and stage III (SPB $\geq 180 \mathrm{mmHg}$ or $\mathrm{DBP} \geq$ $110 \mathrm{mmHg}$ ). Number of patients with SBP $\geq$ 140 and DBP < 90 were determined as isolated uncontrolled systolic hypertension and those with DBP $\geq 90 \mathrm{mmHg}$ and $\mathrm{SBP}<140 \mathrm{mmHg}$, as diastolic hypertension. In our study controlled blood pressure is defined as patient with $\mathrm{SBP}<140 \mathrm{mmHg}$ and $\mathrm{DBP}<90 \mathrm{mmHg}$. At the beginning we analyzed bivariate analysis test ( $x 2$ test) accordingly with sex, age, patient with two or more number of prescribed antihypertensive, angiotensin converting enzyme inhibitors (ACEIs), angiotensin receptor blockers (ARBs), beta blockers, calcium channel blockers (CCBs), diuretics medicine, cardiovascular disease, diabetes and other comborbidities. Secondly logistic regression 
analysis of factors associated with good blood pressure control was done. $\mathrm{P}<0.05$ was considered significant. Inclusion criteria was all the patients was $\geq 18$ years attending in MOPD with hypertension as defined or already under antihypertensive medication and giving consent for study. An exclusion criterion was pregnant women and CKD patient under Mechanical hemodialysis.

\section{Results}

Among the 226 patients male hypertensive are 62 and female hypertensive are 164 patients. 134

(59.29\%) patient were non diabetic hypertension and 92 (40.71\%) were hypertensive with

diabetes mellitus and rest of other comorbidies. Among the 226 patients, 10 patients (4.42\%)

had cardiovascular disease. Heart failure were present in 5 patients, similarly 3 patients had cardiovascular accident. Ischemic heart disease was present in 2 patients in our study. Among the 134 of non diabetic hypertensive only 67 patients i.e. $50 \%$ had blood pressure < 140/90 mmHg. Diabetic hypertensive patients (12 patients) were below < 130/80 $\mathrm{mmHg}$. 78 patients had good blood pressure control noted as $34.5 \%$ in our study. 95 patients were at stage I (64.1\%) and 53 patients were at stage ॥ (35.8\%) among patients with uncontrolled hypertension. Thiazides were the most common diuretics drugs used $48.6 \%$. More than 2 antihypertensive medicines were found to have been used in 158 patients (69.9\%) and amlodipine was used in 155 patients (68.58\%). CCB was single drug of choice for controlled hypertension. 120 patient (53\%) had used Losartan. The above mentioned medicines are antihypertensive medications prescribed and listed in Table 1. Our study shows that, predictors of blood pressure control were significantly control BP $(x 2 ; p<0.05)$ in diabetes status. Bivariate analysis of the association between blood pressure control and other study are summarized in Table 2. CCB was significantly associated with well-controlled blood pressure in multivariate analysis, (OR, 1.93; $95 \% \mathrm{Cl}$, 1.06, 3.51). However, the odds ratio of good control were significantly reduced if the patient were aged 60 years and over (OR, 0.51; 95\% Cl, 0.29, 0.89), diabetes (OR, $1.24 ; 95 \% \mathrm{Cl}, 0.73,2.11)$ and number of prescribed antihypertensive drugs (OR, 1.88; $95 \% \mathrm{Cl}, 1.08,3.27)$. Table 3 indicate the results of logistic regression analysis.

\section{Discussion}

In our study we found that $46.9 \%$ of the hypertensive patients, on follow up, in western regional hospital had controlled blood pressure in the target range. In a study of Pandey et al in 1981 Prevalence of hypertension was $28.9 \%$ (male, 28.8\%; female $30 \%)$. [9, 10]. Another study of national referral hospital (Kenyatta National Hospital) in 2009 shows 26\% blood pressure under control in hypertensive patients [11]. The follow-up hypertensive patients at Nyeri Provincial General Hospital had controlled blood pressure as $33.4 \%$ [12].

In a study of USA in 2000, study shows hypertensive patients with controlled SBP and DBP were $32.7 \% \quad 82.9 \%$ respectively 
[13]. There are several trials that have been documented which show benefits of reduction of systolic blood pressure [14, 15, 16]. Multivariate analysis showed that in old age and/or diabetes the use of three or more drugs had significantly poor blood pressure control. An important risk factor of poor blood pressure control has been identified as older age $[17,18]$. When comparing both groups (diabetic and non diabetic) both groups were significantly likely to have poorly controlled blood pressure. There are similar studies with results of poor control of blood pressure in both non diabetic and diabetic group [19, 20, 21]. A lot of evident based studies show that two or more combination of antihypertensive medicine is needed to adequately control the blood pressure [22].

Poor blood pressure control and Multi drugs regimens has been demonstrated by knight et al. 2001 studies. Ambulatory patients between multidrugs regimen and poor blood pressure control were found to have positive BP control. Patients were likely to have higher blood pressure control who takes four or more antihypertensive than single drug medication [23].

Duggirala et al. found that $35 \%$ more likely to have poor blood pressure controlled the patients who are taking three or more drugs. [24]. CCB was associated with blood pressure control and patients taking CCB were twice likely to have well blood pressure control than those who were not taking $C C B$. Those finding of $C C B$ are more beneficial related with other studies to achieving blood pressure control which are especially in the elderly. $[25,26]$.

\section{Conclusion}

Efficacy of anti hypertensive medication patients study shows that a majority of hypertensive patients in Pokhara Academy of Health Sciences have poorly controlled blood pressure. Diabetes and elderly patients are less likely to have blood pressure controlled, high rate to have complication and need close monitoring. Both Systolic and diastolic blood pressures are high in our study and need targeted intervention to address the problem. Calcium channel blockers were shown to have better blood pressure control in our study. Still further research is needed to address the evidence of a good blood pressure control by CCB. 
Table: 1 . Antihypertensive medication use by patients

Drugs CCBs percentage

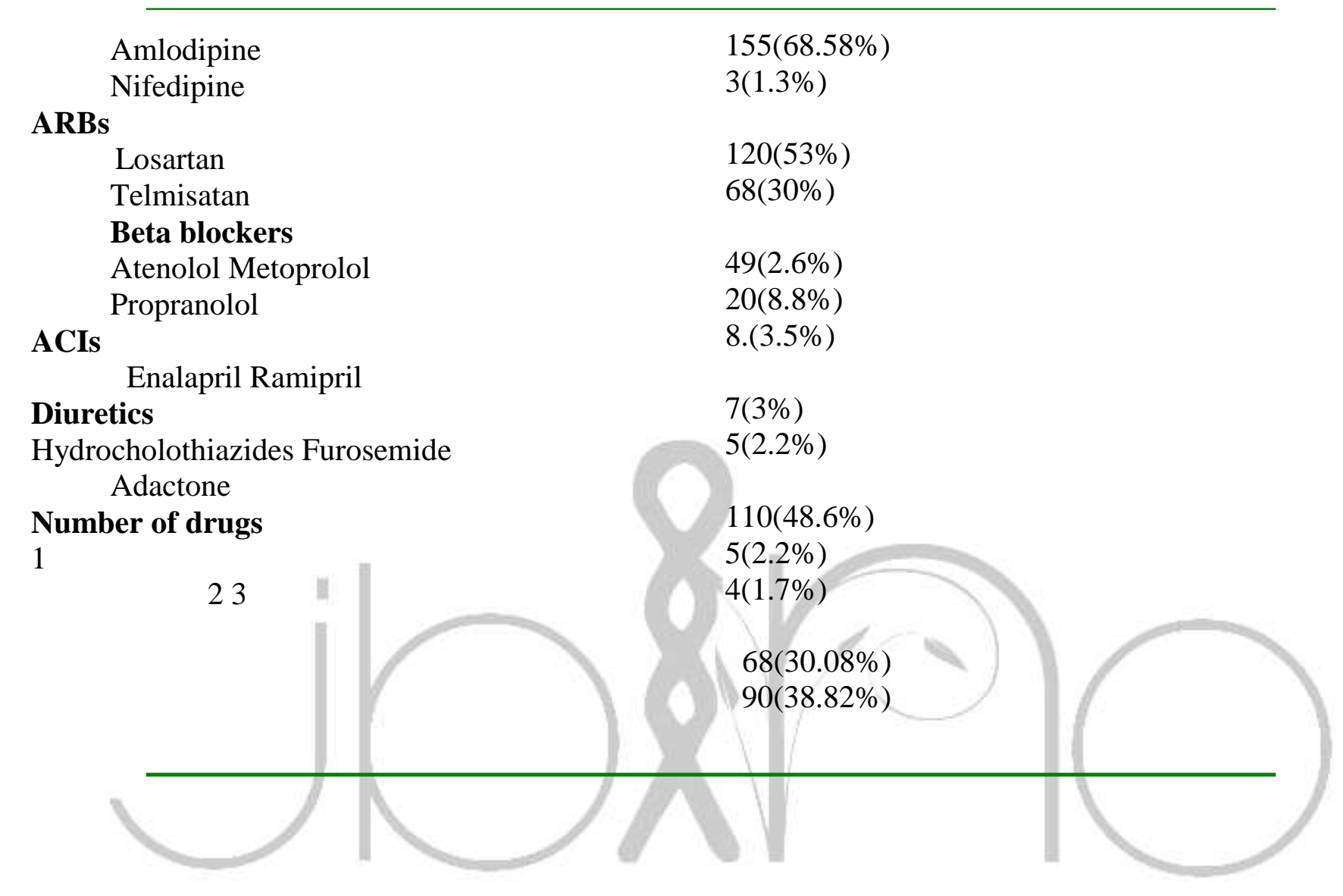

2021 January Edition | www.jbino.com | Innovative Association 
Table 2. Bivariate analysis of the association between blood pressure controls

Variable

Sex

Male

Female

Age

$<60$ years

$>60$ years

Number of drugs used

$<2 \quad 136$

$>3$

on CCBs

Yes

No

ARBs

Yes

No

\section{Beta blocker}

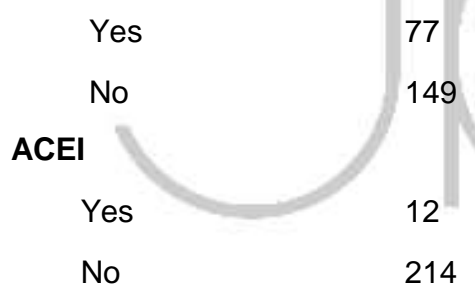

Diuretics

Yes

No

\section{Cardiovascular disease}

$\begin{array}{ll}\text { Yes } & 10 \\ \text { No } & 216\end{array}$

Diabetes

Yes

No

Other co-morbidities

Present

Absent

90

158

68

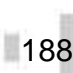

38

77

149

12

214

119

107

10

216

91

135

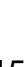

211

$$
\text { Total }
$$

BP Controlled \%

BP Uncontrolled\%

$P$ value

0.46

$62 \quad 25(40.3)$

$164 \quad 75(45.7)$

$81 \quad 40(49.3)$

$14595(65.5)$
66(48.6)

30(33.3)

76(48.1)

22(32.3)

$71(37.7)$

17(44.7)

29(37.6)

69(46.3)

5(41.6)

103(48.1)

53(44.5)

42(39.2)

4(40)

94(38.8)

33(36.2)

67(49.6)

6(40)

93(44)
37(59.7)

89(54.3)

0.01

41(50.7)

50(34.5)

\subsection{2}

70(51.4)

60(66.7)

0.02

82(51.9)

46(67.7)

0.42

117(62.3)

21(55.3)

48(62.4)

80(53.7)

7(58.4)

111(51.9)

\subsection{1}

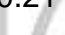

0.66

0.42

66(55.5)

65(68.9)

0.82

6(60)

122(61.2)

0.05

58(63.8)

68(50.4)

0.75

9(60)

118(56) 
Fig: 3 Logistic regression analysis with good blood pressure control

Variable

On Calcium channel blocker

Number of prescribed antihypertensive drugs

Diabetes

\section{OR $(95 \%$}

confidence interval)

$1.93(1.06,3.51)$

$1.88(1.08,3.27)$

$1.24(0.73,2.11)$

$0.51(0.29,0.89)$
$P$ value

0.001

0.001

0.002

0.003

Age

$$
0.51(0.29 .0 .89)
$$

(1)

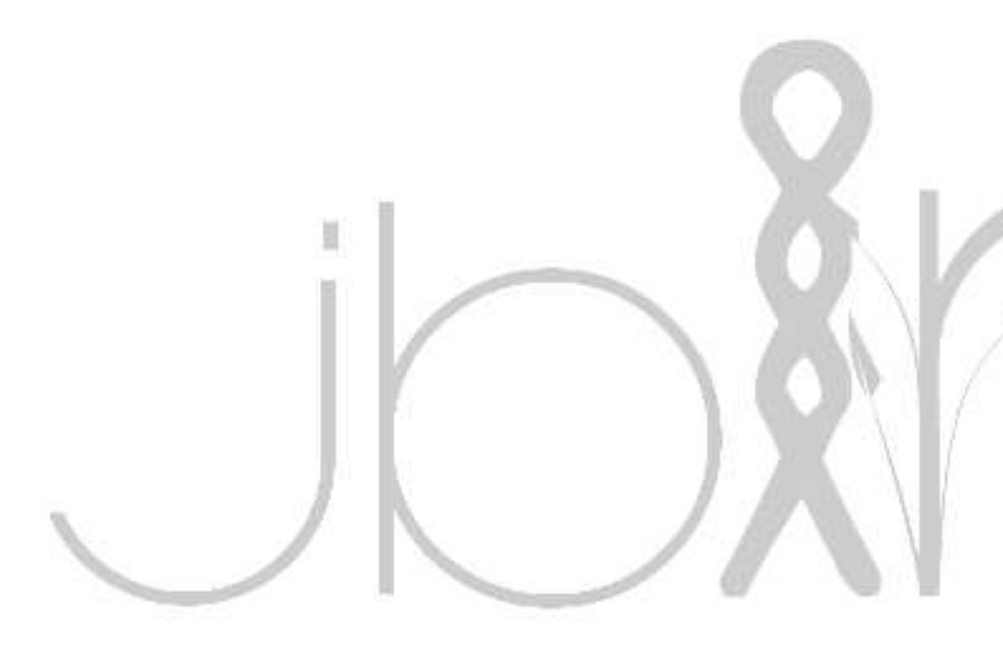

2021 January Edition | www.jbino.com | Innovative Association 


\section{Reference:}

1. World Health Organization. Global status report on non communicable diseases 2010: Description of the global burden of NCDs, their risk factors and determinants. Italy: World Health Organization; $201176 \mathrm{p}$.

2. Whitworth JA. 2003 World Health Organization (WHO)/International Society of Hypertension (ISH)statement on management of hypertension. Journal of hypertension. 2003 Nov;21 (11):1983-92.

3. Williams B, Poulter NR, Brown MJ, Davis $M$, Mclnnes GT, Potter JF et al. British Hypertension Society guidelines for hypertension management 2004 (BHS-IV): summary. Bmj. 2004 Mar 13; 328(7440):63440.

4. Ogden LG, He J, Lydick E, Whelton PK et al. Long-term absolute benefit of lowering blood pressure in hypertensive patients according to the JNC VI risk stratification. Hypertension. 2000 Feb;35(2):539-43.

5. Neal B, MacMahon S, Chapman $\mathrm{N}$ et al. Effects of ACE inhibitors, calcium antagonists, and other blood-pressurelowering drugs: results of prospectively designed overviews of randomised trials Blood Pressure Lowering Treatment Trialists' Collaboration. Lancet. 2000 Dec 9; 356(9246):1955-64.
6. Mathenge W, Foster A, Kuper $\mathrm{H}$ et al. Urbanization, ethnicity and cardiovascular risk in a population in transition in

Nakuru, Kenya: a population-based survey. BMC public health. 2010;10(1):569.

7. Dinesh Neupane, Bindu Panthi, Craig S. McLachlan, Shiva Raj Mishra, Brandon A. Kohrt5, Per Kallestrup et al. Prevalence of Undiagnosed Depression among Persons with Hypertension and Associated Risk Factors: A Cross-Sectional Study in Urban Nepal. PLOS ONE DOI:10.1371/journal.pone.0117329 February 11,2015

8. Suraj Shakya-Vaidya, Umesh Raj Aryal, Madan Upadhyay and Alexandra Krettek et al. Do non-communicable diseases such as hypertension and diabetes associate with primary open-angle glaucoma? Insights from a case control study in Nepal: Glob Health Action 2013, 6: 22636

9. Pandey MR, Upadhyaya LR, Dhungel $S$, Pillaik K, Regmi HN, Neupane RP. Prevalence of Hypertension in a rural community in Nepal. Indian Heart Journal. 1981 Nov-Dec. 33(6): 284-289.

10. Pandey MR. Hypertension in Nepal. Bibl Cardiol. 1987; 42:68-76.

11. Acheing L, Joshi MD, Ogola EN, Karari E. Adequacy of Blood Pressure Control and Level of Adherence with Antihypertensive Therapy. East African 
medical journal. 2009:86(11). PubMed | Google Scholar

12. Ernest Muthami Mutual, \&, Moses Mwangi Gitongal, Beth Mbuthia2, Nelly Muiruri2, Joyce JebetCheptum 1, Thomas Maingi;

13. Lloyd-Jones DM, Evans JC, Larson MG, O'Donnell CJ, Roccella EJ, Levy D. Differential Control of Systolic and Diastolic Blood Pressure: Factors Associated With Lack of Blood Pressure Control in the Community. Hypertension. 2000 October 1;36(4):594-9. PubMed Google Scholar.

14. SHEP Cooperative Research Group. Prevention of stroke by antihypertensive drug treatment in older persons with isolated systolic hypertension - Final results of the Systolic Hypertension in the Elderly Program (SHEP). JAMA: the journal of the American Medical Association. 1991 Jun 26; 265(24):3255-64. PubMed | Google Scholar

15. Staessen JA, Fagard R, Thijs L, Celis $H$, Arabidze GG, Birkenhager $W H$, et al. Randomised double-blind comparison of placebo and active treatment for older patients with isolated systolic hypertension - The Systolic Hypertension in Europe (SystEur) Trial Investigators. Lancet. $1997 \mathrm{Sep}$ 13;350(9080):757-64. PubMed | Google Scholar

16. Liu L, Wang JG, Gong L, Liu G, Staessen JA. Comparison of active treatment and placebo in older Chinese patients with isolated systolic hypertension - Systolic Hypertension in China (Syst-China) Collaborative Group. Journal of hypertension. 1998 Dec;16(12 Pt 1):1823-9. PubMed | Google Scholar.

17. Hyman DJ, Pavlik VN. Characteristics of patients with uncontrolled hypertension in

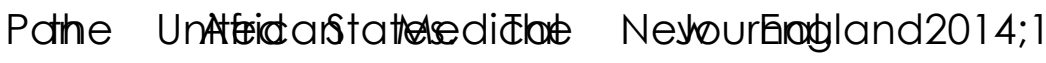
journal of medicine. 2001 Aug 16:345(7):479-86. PubMed | Google Scholar.

18. Ornstein SM, Nietert PJ, Dickerson LM. Hypertension management and control in primary care: a study of 20 practices in 14 states. Pharmacotherapy. 2004 Apr;24(4):500-7. PubMed | Google Scholar

19. Majernick TG, Zacker C, Madden NA, Belletti DA, Arcona S. Correlates of hypertension control in a primary care setting. American journal of hypertension. 2004 Oct;17(10):915-20. PubMed | Google Scholar

Page number not for citation purposes 7

20. MCDonald MV, Pezzin LE, Peng TR, Feldman $\mathrm{PH}$. Understanding the complexity of hypertensive African American home care patients: challenges to intervention. Ethnicity \& disease. 2009 Spring;19(2):148-53. PubMed | Google Scholar.

21. Olomu AB, Gourineni V, Huang JL, Pandya N, Efeovbokhan N, Samaraweera $\mathrm{J}$, et al. Rate and Predictors of Blood Pressure Control in a Federal Qualified Health Center in Michigan: A Huge Concern? The Journal of Clinical 
Hypertension. 2013;15(4):254-63. PubMed | Google Scholar

22. Flack JM, Sica DA, Bakris $G$, Brown AL, Ferdinand $\mathrm{KC}$, Grimm $\mathrm{RH} \mathrm{Jr}$, et al. Management of high blood pressure in Blacks: an update of the International Society on Hypertension in Blacks consensus statement. Hypertension. 2010 Nov;56(5):780- 800. PubMed | Google Scholar.

23. Knight EL, Bohn RL, Wang PS, Glynn RJ, Mogun H, Avorn J. Predictors of uncontrolled hypertension in ambulatory patients. Hypertension. 2001 Oct;38(4):809-14. PubMed | Google Scholar

24. Duggirala MK, Cuddihy RM, Cuddihy MT, Naessens JM, Cha SS, Mandrekar JN et al. Predictors of blood pressure control in patients with diabetes and hypertension seen in primary care clinics. American journal of hypertension. 2005 Jun;18(6):8338. PubMed | Google Scholar.

25. Haller $H$. Effective management of hypertension with dihydropyridine calcium channel blocker-based combination therapy in patients at high cardiovascular risk. International journal of clinical practice. 2008 May;62(5):78190.PubMed | Google Scholar

26. Morgan TO, Anderson Al, Maclnnis RJ. ACE inhibitors, betablockers, calcium blockers, and diuretics for the control of systolic hypertension. American journal of hypertension. 2001 Mar;14(3):241-7. PubMed | Google Scholar 